DIE ITALIENISCHE HOFOPER IN BERLIN UM 1800 


\author{
Christoph Henzel
}

\title{
DIE ITALIENISCHE HOFOPER IN BERLIN UM 1800
}

Vincenzo Righini als preußischer Hofkapellmeister 
Diese Arbeit wurde 1993 in geringfügig abweichender Form unter dem Titel "Die Opere serie Vincenzo Righinis. Untersuchungen zur großen italienischen Oper in Berlin um 1800« an der Hochschule der Künste Berlin (Fachbereich 8:

Musikerziehung und Musikwissenschaft) als Dissertation angenommen. In der gedruckten Fassung widme ich sie meiner Frau Brigitte Weber-Henzel.

Christoph Henzel

Die Deutsche Bibliothek - CIP-Einheitsaufnahme

Henzel, Christoph:

Die italienische Hofoper in Berlin um 1800 : Vincenzo

Righini als preussischer Hofkapellmeister / Christoph

Henzel. - Stuttgart ; Weimar : Metzler, 1994

Zugl.: Berlin, Hochsch. für Bildende Künste, Diss., 1993 u. d. T.

Henzel, Christoph: Die Opere serie Vincenzo Righinis

ISBN 978-3-476-01263-0

\author{
ISBN 978-3-476-01263-0 \\ ISBN 978-3-476-03565-3 (eBook) \\ DOI $10.1007 / 978-3-476-03565-3$
}

Dieses Werk einschließlich aller seiner Teile ist urheberrechtlich geschützt. Jede

Verwertung außerhalb der engen Grenzen des Urheberrechtsgesetzes ist ohne

Zustimmung des Verlages unzulässig und strafbar. Das gilt insbesondere für Vervielfältigungen, Übersetzungen, Mikroverfilmungen und die Einspeicherung und Verarbeitung in elektronischen Systemen.

(C) 1994 Springer-Verlag GmbH Deutschland

Ursprünglich erschienen bei J. B. Metzlersche Verlagsbuchhandlung und Carl Ernst Poeschel Verlag GmbH in Stuttgart 1994 


\section{Inhaltsverzeichnis}

Einleitung

I Die italienische Hofoper in Berlin 1786 - 1807

1 Kapelletat und Repraesentatio maiestatis

2 Opernhaus und Publikum

3 Spielzeit und Spielplan

4 Organisation und Produktion $\quad 49$

5 Die Sängerinnen und Sänger $\quad 61$

6 Das Orchester der Hofoper $\quad 67$

$\begin{array}{lll}7 & \text { Das Ballett } & \mathbf{7 3}\end{array}$

8 Vincenzo Righini: der Hofkapellmeister $\quad \mathbf{8 1}$

8.1 Die große Oper . . . . . . . . . . . . . . . . 81

8.2 Die Opera buffa . . . . . . . . . . . . . . . . 84

8.3 Gelegenheitskompositionen für den Hof . . . . . . . . . . 86

9 Vincenzo Righini: Mensch und Künstler $\quad 89$

9.1 Anstellung in Berlin . . . . . . . . . . . . . . 90

9.2 Die Familie . . . . . . . . . . . . . . . . . 91

9.3 Das Berliner Musikleben . . . . . . . . . . . . . 93

9.4 Righini im Musikleben anderer deutscher Städte . . . . . . . . 96

9.5 Urteile über den Opernkomponisten . . . . . . . . . . . . . . . . . 97

$\begin{array}{ll}\text { II Die Libretti } & 101\end{array}$

10 Der preußische Hofpoet 105 
11 Enea nel Lazio. Dramma eroi-tragico (1793) 111

11.1 Der Inhalt . . . . . . . . . . . . . . . . . 111

11.2 De'Filistris Bearbeitung des Aeneas-Stoffes . . . . . . . . . 115

11.3 Die Rollen . . . . . . . . . . . . . . . . . . . . . 120

11.4 Der Bauplan . . . . . . . . . . . . . . . . . . 123

11.5 Rezitative und Arien . . . . . . . . . . . . . . . 127

11.6 Die Ensembles . . . . . . . . . . . . . . . . 130

11.7 Komplexe Szenen . . . . . . . . . . . . . . . . . 133

$12 \mathrm{Zu}$ den übrigen Libretti $\quad \mathbf{1 3 7}$

12.1 Il trionfo d'Arianna. Dramma (1793) . . . . . . . . . . . 137

12.2 Armida. Dramma (1797) . . . . . . . . . . . . 143

12.3 Tigrane. Dramma eroi-tragico $(1800) \ldots \ldots$. . . . . . . 150

12.4 La selva incantata/Gerusalemme liberata

o sia Armida al campo de'Franchi. Dramma (1803) . . . . . . . . 156

\section{Die Kompositionen 163}

13 Die Partituren $\quad 167$

13.1 Enea nel Lazio $(1793,1794) \ldots \ldots$. . . . . . . . . . . . . . . . . . . . . . . . . . . . . . .

13.2 Il trionfo d'Arianna $(1793,1796) \ldots \ldots$. . . . . . . . . . . 170

13.3 Armida $(1782,1788$ ?, 1797, 1799) . . . . . . . . . . . 171

13.4 Tigrane $(1800 / 1802) \ldots \ldots \ldots \ldots . \ldots \ldots$

13.5 La selva incantata/Gerusalemme liberata. (1803/1811/um 1815) . 176

14 Ouvertüre, Einleitung und Introduzione $\quad 179$

15 Die Rezitative $\quad 185$

16 Die Arien $\quad 195$

16.1 Arienformen . . . . . . . . . . . . . . . 196

16.2 Lavinias Arie Dove andò? che vidi mai? (Enea nel Lazio II.9.) . . 200

16.3 Melodik und Orchestersatz . . . . . . . . . . . . . . 205

16.4 Eine Doppelvertonung . . . . . . . . . . . . . . . 211 
A Quellenverzeichnis $\quad \mathbf{2 4 3}$

A.1 Partituren (Opern Vincenzo Righinis) . . . . . . . . . . . . . 243

A.2 Libretti und Programmbücher . . . . . . . . . . . . . . . 244

A.3 Archivmaterial . . . . . . . . . . . . . 246

A.4 Literatur . . . . . . . . . . . . . . . . . . 248

B Das Personal der italienischen Hofoper in Berlin (1786 - 1810) 261

B.1 Direktion . . . . . . . . . . . . . . . 262

B.2 Sängerinnen und Sänger der Großen Oper . . . . . . . . . . . . . 264

B.3 Orchester .......................... 267

C Die Wohltätigkeitskonzerte $\begin{array}{ll}\text { der Königlichen Kapelle }(1799-1806) & 277\end{array}$

D Vincenzo Righini, Lavinias Arie Dove andò? che vidi mai? (Enea nel Lazio II.9.) 